\title{
CONTROLE DE QUALIDADE DE MADEIRAS DA REGIÃo AMAZÔNICA 1
}

\section{João Peres Chimelo2}

\begin{abstract}
RESUMO - O grande número de espécies encontrado nas florestas tropicais úmidas tem sido mencionado freqüentemente como um dos principais obstáculos a uma utilização mais intensiva da madeira em países em desenvolvimento. Este trabalho descreve dois exemplos de como o conhecimento da anatomia e das propriedades físicas e mecânicas das espécies abundantes, aliado a um esquema adequado de controle de qualidade, pode viabilizar uma maior utilização de madeiras da amazônia brasileira. O primeiro exemplo se refere à produção de dormentes para a Estrada de Ferro Carajás (E.F.C.) com $890 \mathrm{~km}$ de extensão, onde foram empregados cerca de 2.100 .000 dormentes; o segundo trata do uso de madeira serrada para habitação de baixo custo, no Estado de São Paulo, cuja construção é administrada pelas Companhias Habitacionais - COHABs. Palavras-chave: Madeiras amazônicas, Dormentes, Habitações, Controle de Qualidade.
\end{abstract}

\begin{abstract}
The large number of species usually found in tropical rain forests has been frequently mentioned as one of the main obstacles to a better utilization of wood as a construction material in developing countries. This paper describes two examples of how the knowledge about anatomical features and technological properties, together with an adequate quality controle scheme, made possible greater utilization of Amazon species. One of these examples is the production of sleepers for the Estrada de Ferro Carajás (Carajás Rail Road), $890 \mathrm{~km}$ (560 miles) long that used about 2.1 million cross ties; the is the use of sawn timber in low cost housing in the State of São Paulo, built under the supervision of State Housing Companies - COHABs.

Key words: Amazonian woods, Crossties, Housing, Quality Control.
\end{abstract}

\section{Introdução}

O presente trabalho faz uma abordagem sobre o controle de qualidade de madeiras da região amazônica, enfocando principalmente a obtenção de dormentes ferroviários - no caso mais recente da construção da Estrada de Ferro Carajás - EFC, que liga a Serra de Carajás - Sul do Pará, ao Porto de Itaqui, em São Luis, MA, bem como sobre madeiras empregadas em construção civil, no Estado de São Paulo, especificamente para construções habitacionais populares, administratadas pelas Companhias Habitacionais - COHABs.

Bastos (1966) salienta que os dormentes constituem uma parte importantíssima da superestrutura das linhas férreas, pois são responsáveis pela fixação dos trilhos, manutenção da bitola, amortecimento, distribuição das cargas rolantes e, ainda, isolamento dos circuitos elétricos de sinalização.

Numa ferrovia, a dormentação de suas linhas, assim como o material rodante, as obras de arte e demais equipamentos, têm de ser da melhor qualidade.

Na cidade de Belém, PA, estabeleceu-se a primeira empresa que cuidava dos negócios de dormentes. De um total de 6.000 ton. exportado, em 1917, passou para 97.000 ton. em 1930, caindo daí por diante por dois motivos:

- má seleção do produto.

- falta de classificação do mesmo, quanto às espécies botânicas e aspectos de apresentação.

Os dormentes da região amazônica, que nunca deixaram de ser exportados para outros países, não interessavam aos consumidores nacionais por temerem adquirir um material cuja identificação não era simples.

\footnotetext{
1 Trabalho apresentado no Workshop Internacional sobre Anatomia de Madeira dos Países Membros do Tratado de Cooperação Amazônica, realizado durante o XXXIX Congresso Nacional de Botânica, em Belém, PA, de 25 a 31/01/88.

2 I.P.T. - Divisão de Madeiras - Chefe de Agrupamento de Anatomia e Identificação - C.P. 7141 CEP 05508 - São Paulo, SP.
} 
Freitas (1982) comenta que, embora a Amazônia Brasileira seja considerada a maior reserva florestal tropical do mundo, com cerca de 340 milhões de ha somente nos últimos anos é que esta reserva está abastecendo os mercados de outras regiões do Pais, principalmente as regiões Nordeste, Sudeste e Sul. Até há pouco tempo, especificamente as duas últimas regiões eram supridas quase que exclusivamente pelas madeiras de pinhodo-paraná - Araucaria angustifolia Bert. O. Kuntze, Araucariacea, peroba-rosaAspidosperma polyneuron Muell. Arg., Apocynaceae, hoje bastante escassas devido ao esgotamento de suas fontes: norte do Paraná e sul do Mato Grosso do Sul.

A madeira de peroba-rosa, que é hoje quase toda importada do Paraguai, está ficando cada vez mais cara e, conseqüentemente, grande parte das madeiras consumidas nas regiões acima mencionadas está vindo da Amazônia.

Freitas \& Chimelo (1982) comentam que, nos primeiros estágios de planejamento da construção da EFC, havia sérias dúvidas a respeito do verdadeiro potencial da floresta amazônica em fornecer a quantidade e qualidade dos dormentes requeridos por essa ferrovia. Temendo que houvesse atrasos na sua construção, alguns especialistas eram a favor de se usar dormentes importados e tratados ou mesmo dormentes de concreto.

$\mathrm{O}$ início da aquisição dos 2.100 .000 dormentes empregados na construção da EFC, com 890 km de extensão, data de outubro de 1981 e a sua inauguração, de 28 de fevereiro de 1985 .

Segundo B. Neto et al. (1983), a base para esta experiência bem sucedida teve 2 (dois) componentes principais.

1. avaliação criteriosa dos recursos florestais e da capacidade industrial dos produtores de dormentes da região amazônica;

2. inspeção efetiva e procedimentos de controle de qualidade, baseando-se em especificações técnicas apropriadas, em todos os níveis de produção.

$\mathrm{O}$ primeiro passo quanto à seleção das madeiras amazônicas que seriam empregadas na construção da EFC consistiu numa consulta à literatura disponível, com base nos trabalhos de Bastos (1966) e Pereira \& Mainieri (1949), a fim de se obter o máximo de informações quanto à adequabilidade dessas madeiras, com relação principalmente às suas características de resistência mecânica e durabilidade natural.

As madeiras consideradas com qualidades potenciais, porém, ainda não estudadas, foram submetidas aos seguintes testes de laboratório, na Divisão de Madeiras do Instituto de Pesquisas Tecnológicas do Estado de São Paulo S.A. - IPT, em São Paulo - SP:

1. Ensaios físicos e mecânicos: densidade, retratibilidade volumétrica e linear, módulo de elasticidade na compressão nos planos radial e tangencial, tração normal às fibras, dureza Janka, módulo de elasticidade na flexão e arrancamento de fixação do tirefão.

Como padrão mínimo de resistência mecânica foi tomada como base a madeira de peroba-rosa, cujo comportamento mecânico como dormente é considerado satisfatório nas ferrovias das regiões Sudeste e Sul do País.

2. Ensaios de durabilidade natural e permeabilidade a soluções preservantes: apodrecimento acelerado, resistência a cupim e impregnação por pressão, através do Processo Bethell. Foram, também, realizados testes de secagem ao ar, no campo, a fim de se obter a curva de secagem para cada espécie selecionada. Defeitos de secagem como empenamento e rachaduras severas foram também registrados.

$\mathrm{O}$ primeiro parâmetro para se aceitar uma espécie foi sua resistência mecânica. Se uma espécie potencial apresentasse propriedades mecânicas iguais ou superiores às da peroba-rosa, ela era aceita.

O segundo parâmetro era a durabilidade natural do cerne. Se este mostrasse boa resistência ao ataque de insetos e a fungos apodrecedores, então a espécie era aceita. Caso esta resistência não fosse satisfatória, porém o cerne mostrasse boa permeabilidade ao tratamento sob pressão, a espécie era aceita. De acordo com este critério, foram formados 2 grupos de madeiras aceitas para dormentes, conforme a Tabela 1, anexa: 
O GRUPO I - reunindo 17 espécies de madeiras que apresentavam propriedades físico-mecânicas e de durabilidade natural consideradas ideais para a produção de dormentes, cujos resultados de utilização prática confirmam tal avaliação.

O GRUPO II - reunindo 23 espécies de madeiras cujo comportamento, por motivos diversos, não atinge o mesmo nível das madeiras do Grupo I.

As espécies constantes da Tabela I constituiram a base para a elaboração da Especificação de Recebimento de Dormentes da CVRD - Companhia Vale do Rio Doce EM 2.000-18-900, segundo a qual foram adquiridos os 2.100.000 dormentes empregados na construção da EFC.

Com relação à qualificação dos fornecedores, como apoio à CVRD no julgamento das concorrências, foram feitas visitas técnicas nas empresas que participaram dessas concorrências, a fim de obter-se informações sobre a capacidade de produção, o nível técni$\mathrm{co}$, as condições gerais do contexto composto de florestas, infra-estrutura, equipamentos, pessoal e experiência no setor. Dessa forma, as várias empresas foram classificadas quanto ao seu potencial de atendimento da demanda de dormentes pela CVRD. Com a finalidade de se conseguir uma grande produção e permitir a participação de serrarias menores, um sistema de consórcio foi estabelecido, no qual tomavam parte 14 (quatorze) serrarias.

Com relação às madeiras empregadas pela indústria da construção civil, nas regiões Sudeste e Sul do País, especificamente nos setores de edificação e habitação, o pinho ou araucária, o cedro (Cedrella spp, Meliaceae), a peroba-rosa e as canelas (Ocotea spp e Nectandra spp - Lauraceae), eram, basicamente, até há pouco tempo, aquelas tradicionalmente utilizadas.

De acordo com Soares (1981), na verdade, o construtor dificilmente ia além desse universo quando realizava uma obra, da armação das formas e escoramento até o uso de lâminas decorativas.

Uma das principais causas desse uso limitado de madeiras era o desconhecimento da existência de madeiras alternativas que preenchessem as exigências de qualidade para cada caso especifico de uso.

Várias instituições nacionais como o IPT - Instituto de Pesquisas Tecnológicas do Estado de São Paulo S.A., o INPA - Instituto Nacional de Pesquisas da Amazônia, a SUDAM - Superintendência do Desenvolvimento da Amazônia, o LPF/IBDF - Laboratório de Produtos Florestais/Instituto Brasileiro de Desenvolvimento Florestal de Brasília, os Laboratórios de Madeiras da Escola de Engenharia de São Carlos, do Curso de Engenharia Florestal de Piracicaba, da Escola de Engenharia Florestal de Curitiba, do Setor de Tecnologia de Madeiras de Cuiabá e outros, vêm estudando, de longa data, as propriedades tecnológicas das madeiras nacionais, a fim de que os usuários possam conhecer as resistências das nossas principais madeiras comerciais e poderem empregar outras madeiras alternativas em substituição àquelas madeiras tradicionais já em vias de extinção.

\section{Material e Métodos}

a. Material.

O material deste trabalho se refere a dormentes ferroviários de madeira, obtidos de várias espécies, bem como madeira serrada, na forma de vigas, caibros e ripas, para estrutura de cobertura em construções habitacionais populares.

As madeiras para este último tipo de uso procedem das regiões Norte e Centro-Oeste do País.

b. Métodos.

Os dormentes foram inspecionados, individualmente, junto a cada fonte de produção (serraria), sendo examinados visualmente em todas as suas faces, identificando-se 
as espécieis de madeiras aceitas, contidas na lista da Especificação de Recebimento de Dormentes da CVRD, através do processo macroscópicos, bem como a verificação das dimensões e defeitos dos dormentes recém-cortados. Uma vez aprovado o dormente, este recebia, num dos topos, um carimbo com a sigla do órgão inspetor e, no outro, com a sigla do órgão comprador. Cada firma produtora colocava também o seu carimbo nos dois topos dos dormentes que produzia. Eram feitas também coletas de amostras dos produtos concentrados e da solução usada no pré-tratamento preservante dos dormentes, segundo um sorteio prévio das serrarias fornecedoras.

Depois de serem inspecionados nas serrarias fornecedoras, os dormentes eram transportados para os pátios de secagem e $25 \%$ deles eram re-inspecionados quanto à espécie, às dimensões, à forma e aos defeitos. A seguir eram empilhados em pilhas de $9 \times 1$ dormentes, contendo 100 dormentes por pilha e assim ficavam expostos para secagem ao ar. Estas pilhas eram pulverizadas com uma solução de creosoto + óleo BDF na proporção e $50 \%$ em volume. Este tipo de pré-tratamento mostrou-se satisfatório, pois a incidência de ataque de fungos e insetos foi bastante branda, ao redor de 2,5\% e não causou rejeição de nenhuma peça.

Segundo as observações de B. Neto et al. (1983) os defeitos de secagem eram avaliados no final do período de secagem de cada lote, justamente antes das operações de entalhe e furação. Os principais defeitos observados foram rachas longitudinais e anelares. $\mathrm{O}$ total de perdas devidas aos defeitos de secagem foi de cerca de $0,15 \%$.

A qualidade de cada embarque de creosoto e solvente de petróleo recebidos na UTD - Usina de Tratamento de Dormentes, conforme esse mesmo autor, era analisada de acordo com as normas da American Wood Preservers Association - AWPA, bem como a solưção dos tanques de trabalho era analisada uma vez por semana, de acordo também com as recomendações dessa Associação.

Ainda conforme B. Netto et al. (1983) todas as operações na UTD, de cada lote de tratamento, eram controladas diariamente através da análise dos dados das respectivas fichas de tratamento. O tratamento padrão seguiu o Processo Bethell com 30 minutos de vácuo inicial (635 mm Hg), 60 minutos de pressão $(12,6 \mathrm{kgf} / \mathrm{cm} 2)$ e 10 minutos de vácuo final $(635 \mathrm{~mm} \mathrm{Hg})$.

A retenção da solução preservante nos dormentes tratados era determinada, segundo B. Neto et al. (1983) pela secagem períodica de um lote de dormentes da mesma espécie antes e depois da operação de tratamento, tomando o cuidado de determinar a porcentagem de alburno.

Com a finalidade de se confirmar preliminarmente as retenções obtidas pelo ganho de peso, eram retiradas amostras com o trado de incremento da região do alburno dos dormentes tratados e analisadas no laboratório.

Sendo as proporções de alburno bastante variáveis nos dormentes e sendo o cerne da maioria das espécies impermeável à solução preservante, a retenção média obtida era bastante baixa, ao redor de $3 \mathrm{~kg}$ por dormente.

\section{Resultados}

Depois da construção da EFC, inaugurada em fevereiro de 1985, o uso de dormentes procedentes da região amazônica nas ferrovias de outros Estados do País já é bastante significativo.

O sucesso do emprego de dormentes dessa região, nessa ferrovia, graças à orientação do IPT em todas as etapas, desde a obtenção até a implantação na via férrea, motivou a sua aceitação pelas demais ferrovias nacionais.

Embora as porcentagens iniciais de rejeição fossem altas, em torno de $25 \%$, devido à falta de tradição na produção de dormentes pela maioria das serrarias consorciadas, elas logo caíram para um percentual médio em torno de $10 \%$. 
A Tabela 2 mostra as quantidades inspecionadas, aprovadas e rejeitadas e respectivas porcentagens de refugo, bem como as quantidades aprovadas e respectivas porcentagens por espécie de madeira identificada, para dormentes comuns e especiais, durante as inspeções de todos os dormentes destinados à construção da EFC.

A Tabela 3 mostra as quantidades de dormentes rejeitados, as causas da rejeição (defeitos) e respectivas porcentagens, para dormentes comuns e especiais.

Em recentes inspeções realizadas pelo IPT em várias obras de habitações populares, fiscalizadas por COHABs no Estado de São Paulo, constatou-se a introdução de grande número de espécies de madeiras procedentes da região amazônica.

Inicialmente observava-se não só peças com braçal ou alburno, não permitindo em madeira sem tratamento, como também defeitos tais como: esmoado, furos de broca, racha, podridão, nós cariados, etc e, ainda, madeiras não indicadas para estrutura de cobertura, por apresentarem baixas propriedades de resistência mecânica e ao ataque de organismos xilófagos.

Com a orientação prestada às empreiteiras dessas obras e aos fiscais das COHABs, hoje a situação já melhorou sensivelmente, com o uso de espécies corretas e com um melhor padrão de qualidade.

A Tabela 4 ilustra os tipos predominantes de madeiras identificadas e as quantidades inspecionadas, aprovadas e refugadas, por tipo de peça utilizada em estrutura de cobertura. A Tabela 5 mostra as principais causas de rejeição das peças examinadas durante as várias inspeções realizadas em obras de conjuntos habitacionais populares no Estado de São Paulo.

Observa-se nessa tabela que quase $50 \%$ das madeiras identificadas são procedentes da região amazônica e que a segunda madeira predominante já é o jatobá que, até há pouco tempo, não era empregado em construções habitacionais.

O tradicional peroba-rosa já cedeu seu lugar para o jatobá, muiracatiara e está bem próxima da tatajuba (Bagassa guianensis, Moraceae), todas elas procedentes da região amazônica.

As canelas, marfim (Balfourodendron riedelianum, Rutaceae) e Cedro já estão cedendo seus lugares para várias madeiras da região amazônica.

Quanto aos problemas observados, os dois maiores índices recaem sobre alburno ou branco, com cerca de $52 \%$ e espécies não indicadas, com cerca de $34 \%$, problemas esses que poderão ser eliminados com um trabalho de orientação aos produtores de madeira e execução de controle de qualidades nas fontes de produção.

\section{Conclusões}

Embora nos primeiros estágios do planejamento da implantação da Estrada de Ferro Carajás - EFC houvesse sérias dúvidas por parte de alguns especialistas quanto a adequabilidade das madeiras da região amazônica para a produção de dormentes e quanto à capacidade industrial das serrarias localizadas na área de influência dessa ferrovia, estudos aprofundados efetuados pela Divisão de Madeiras do IPT, quanto às propriedades tecnológicas de várias dezenas dessas madeiras, vieram confirmar que madeiras dessa região são ideais para tal finalidade. Com a orientação prestada pelo IPT à CVRD na preparação da Especificação Técnica para Recebimento de Dormentes, na avaliação da capacidade produtiva dos fornecedores de dormentes e na participação ativa dos trabalhos de inspeção, recebimento e tratamento preservante dos dormentes, foi possível adquirir, com absoluta pontualidade de entrega, os 2.100 .000 dormentes necessários a essa ferrovia, com qualidade equivalente ou superior aos padrões internacionais, o que tem causado interesse por parte dos compradores nacionais e de outros países.

Apesar de terem sido observados muitos problemas com relação à introdução de 
madeiras da região amazônica nas construções habitacionais populares no Estado de São Paulo, fiscalizadas pelas $\mathrm{COHABs,} \mathrm{com} \mathrm{orientação} \mathrm{prestada} \mathrm{às} \mathrm{empreiteiras} \mathrm{dessas} \mathrm{obras}$ e aos fiscais das COHABs, a situação vem melhorando sensivelmente com o uso de espécies corretas e com um melhor padrão de qualidade visando a substituição das madeiras tradicionalmente empregadas, (pinho, peroba, cedro, marfim, canelas), em via de total esgotamento, por madeiras alternativas da região amazônica. Quase $50 \%$ das espécies de madeiras identificadas nessas obras já vêm dessa região e a tradicional peroba já cedeu seu lugar para o jatobá, (Hymenaea spp.), muiracatiara (Astronium lecointeiAnacardiaceae) e está próxima da tatajuba.

Quanto aos problemas observados, os dois maiores índices se referem à presença de alburno ou branco, cerca de $52 \%$ e espécies de madeiras não recomendadas para estrutura de cobertura, cerca de $35 \%$.

Tais problemas poderão ser simplesmente eliminados com uma orientação aos produtores de madeira serrada quanto à identificação correta das madeiras que utilizam e observação das exigências dos compradores, contidas nas ordens de compra.

\section{Referências Bibliográficas}

BASTOS, A. de M. 1966. Madeiras da Amazônia para dormentes. Rio de Janeiro. 88p. FREITAS, A.R. de 1982. Potencial de utilização de madeiras em construções. In: Encontro Brasileiro em Preservação de Madeiras. 1. Palestra Inaugural...

FREITAS, A.R. DE \& CHIMELO, J.P. 1982. Utilização de madeiras amazônicas para a produção de dormentes para o projeto Estrada de Ferro-Carajás. In: Congresso Brasileiro de Essências Nativas. Anais... p. 1316-1327.

B. NETO, O. de et al. 1983. Amazon woods for crosstie production. In. Conferência da Iufro, Madison, USA.

PEREIRA, J.A. \& MAINIERI, C. 1949. Madeiras brasileiras empregadas para dormentes. Anu. Bras. Econ. Florest., Rio de Janeiro, 2(2): 215-251.

SOARES L. 1981. Madeira. Setor já pode identificar os tipos, conforme o uso. A Construção, Rio de Janeiro (184): 38-39. 
Tabela 1. Espécies de madeiras amazônicas aceitas para a produção de dormentes, de acordo com a especificação técnica da CVRD - Em 2000-18-900.

\begin{tabular}{|c|c|}
\hline \multicolumn{2}{|c|}{ GRUPO I } \\
\hline NOME VULGAR & NOME CIENTÍFICO/FAMÍLIA \\
\hline $\begin{array}{l}\text { 1. ACAPU } \\
\text { 2. ANGELIM-VERMELHO } \\
\text { 3. ARARACANGA } \\
\text { 4. CUMARU } \\
\text { 5. IPÊ OU PAU D'ARCO } \\
\text { 6. ITAÚBA } \\
\text { 7. JATOBÁ Ou JUTAÍ } \\
\text { 8. JUTAÍ-POROROCA ou POROROCA } \\
\text { 9. LIMORANA } \\
\text { 10. MACACAÚBA } \\
\text { 11. MUIRAJUBA } \\
\text { 12. PAU-ROXO } \\
\text { 13. PIQUIÁ } \\
\text { 14. PRACUÚBA-DA-VÁRZEA ou } \\
\text { PRACUÚBA-VERMELHA } \\
\text { 15. SUCUPIRA } \\
\text { 16. TATAJUBA } \\
\text { 17. TENTO-PRETO }\end{array}$ & $\begin{array}{l}\text { Vouacapoua americana, Leguminosae } \\
\text { Dinizia excelsa, Leguminosae } \\
\text { Aspidosperma desmanthum, Apocynaceae } \\
\text { Dipteryx odorata, Leguminosae } \\
\text { Tabebuia serratifolia, Bignoniaceae } \\
\text { Mezilaurus itauba, Lauraceae } \\
\text { Hymenaea courbaril, Leguminosae } \\
\text { Dialium guianensis, Leguminosae } \\
\text { Chlorophora tinctoria, Moraceae } \\
\text { Platymiscium ulei, Leguminosae } \\
\text { Apuleia leiocarpa, Leguminosae } \\
\text { Peltogyne maranhensis, Leguminosae } \\
\text { Caryocar villosum, Caryocaraceae } \\
\text { Mora paraensis, Leguminosae } \\
\text { Bowdichia sp/Diplotropis sp, Leguminosae } \\
\text { Bagassa guianensis, Moraceae } \\
\text { Ormosia flava, Leguminosae }\end{array}$ \\
\hline \multicolumn{2}{|c|}{ GRUPO II } \\
\hline NOME VULGAR & NOME CIENTÍFICO \\
\hline $\begin{array}{l}\text { 1. ACAPURANA } \\
\text { 2. ACHUÁ OU ACHUARANA } \\
\text { 3. ANGELIM-PEDRA } \\
\text { 4. ANGELIM-RAJADO } \\
\text { 5. BACURI } \\
\text { 6. CONDURU Ou MUIRAPIRANGA } \\
\text { 7. CUIARANA } \\
\text { 8. CUPIÚBA } \\
\text { 9. FAVA-BOLACHA } \\
\text { 10. FAVA-ORELHA-DE-NEGRO } \\
\text { 11. GOMBEIRA } \\
\text { 12. GUARIÚBA } \\
\text { 13. ITAUBARANA } \\
\text { 14. LOURO-PRETO } \\
\text { 15. MANGUE-VERMELHO } \\
\text { 16. MUIRACATIARA } \\
\text { 17. MUIRAGONÇALO } \\
\text { 18. PAU-AMARELO } \\
\text { 19. PIRANHEIRA } \\
\text { 20. SAPUCAIA } \\
\text { 21. TANIBUCA } \\
\text { 22. UCHI Ou UCHIRANA } \\
\text { 23. UMIRI }\end{array}$ & $\begin{array}{l}\text { Campsiandra laurifolia, Leguminosae } \\
\text { Vantanea sp, Humiriaceae } \\
\text { Hymenolobium petraeum, Leguminosae } \\
\text { Pithecelobium racemosum, Leguminosae } \\
\text { Platonia insignis, Clusiaceae } \\
\text { Brosimum paraense, Moraceae } \\
\text { Terminalia amazonia, Combretaceae } \\
\text { Goupia glabra, Goupiaceae } \\
\text { Vatairea guianensis, Leguminosae } \\
\text { Enterolobium schomburgkii, Leguminosae } \\
\text { Swartzia aptera, Leguminosae } \\
\text { Clarisia racemosa, Moraceae } \\
\text { Acosmium nitens, Leguminosae } \\
\text { Ocotea neesiana, Lauraceae } \\
\text { Rhizophora mangle, Rhizophoraceae } \\
\text { Astronium lecointei, Anacardiaceae } \\
\text { Hieronyma alchorneoides, Euphorbiaceae } \\
\text { Euxylophora paraensis, Rutaceae } \\
\text { Piranhea trifoliata, Euphorbiaceae } \\
\text { Lecythis paraensis, Lecythidaceae } \\
\text { Buchenavia capitata, Combretaceae } \\
\text { Endopleura uchi, Humiriaceae } \\
\text { Humiria floribunda, Humiriaceae }\end{array}$ \\
\hline
\end{tabular}


Tabela 2 - Quantidades Inspecionadas (Q.I.), Quantidades Aprovadas (Q.A.), Quantidades Rejeitadas (Q.R.) e Porcentagens de Refugo (R.\%), bem como quantidades aprovadas e respectivas porcentagens por es pécie de madeira identificada de dormentes comuns e especiais.

\begin{tabular}{|l|c|r|r|r|}
\hline TIPO DE DORMENTES & Q.I. & Q.A. & Q.R. & R.\% \\
\hline DORMENTES COMUNS & 2.256 .029 & 2.028 .753 & 227.276 & 10,07 \\
\hline DORMENTES ESPECIAIS & 41.608 & 35.861 & 5.747 & 13,81 \\
\hline TOTAL & 2.297 .637 & 2.064 .614 & 233.023 & 10,14 \\
\hline
\end{tabular}

\begin{tabular}{|c|c|c|c|c|}
\hline \multicolumn{3}{|l|}{ DORMENTES COMUNS } & \multicolumn{2}{|c|}{ DORMENTES ESPECIAIS } \\
\hline MADEIRA & Q.A. & $\%$ & Q.A. & $\%$ \\
\hline 1. JATOBÁ & 1.349 .016 & 66,50 & 16.137 & 45,00 \\
\hline 2. PIQUIÁ & 191.557 & 9,44 & 12.551 & 35,00 \\
\hline 3. MUIRACATIARA & 172.369 & 8,50 & - & - \\
\hline 4. ANGELIM-VERMELHO & 76.012 & 3,75 & 3.586 & 10,00 \\
\hline 5. ANGELIM-PEDRA & 59.767 & 2,96 & - & - \\
\hline 6. TATAJUBA & 54.985 & 2,71 & 1.435 & 4,00 \\
\hline 7. IPÊ & 24.035 & 1,18 & 717 & 2,00 \\
\hline 8. CUIARANÁ/TANIBUCA & 20.778 & 1,04 & - & - \\
\hline 9. PAU-AMARELO & 18.686 & 0,92 & - & - \\
\hline 10. CUMARU & 14.201 & 0,70 & 717 & 2,00 \\
\hline 11. PAU-ROXO & 13.546 & 0,67 & 359 & 1,00 \\
\hline 12. PRACUÚBA & 6.712 & 0,33 & - & - \\
\hline 13. SAPUCAIA & 3.942 & 0,19 & - & - \\
\hline 14. CUPIÚBA & 3.779 & 0,19 & - & - \\
\hline 15. FAVA-ORELHA- & & & & \\
\hline DE-NEGRO & 3.205 & 0,16 & - & - \\
\hline 16. MAÇARANDUBA & 2.923 & 0,14 & - & - \\
\hline 17. ITAÚBA & 2.669 & 0,13 & - & - \\
\hline 18. MACACAÚBA & 2.434 & 0,12 & - & - \\
\hline 19. UCHI & 2.090 & 0,10 & - & - \\
\hline 20. MUIRAJUBA & 1.770 & 0,09 & - & - \\
\hline 21. GUARIÚBA & 1.073 & 0,05 & - & - \\
\hline 22. SUCUPIRA & 1.009 & 0,05 & 359 & 1,00 \\
\hline 23. BACURI & 953 & 0,05 & - & - \\
\hline 24. ARARACANGA & 656 & 0,03 & - & - \\
\hline 25. ANGELIM-RAJADO & 241 & - & - & - \\
\hline 26. JARANA & 153 & - & - & - \\
\hline 27. FAVA-BOLACHA & 111 & - & - & - \\
\hline 28. GUAJARÁ-PEDRA & 46 & - & - & - \\
\hline 29. CONDURU & 35 & - & - & - \\
\hline TOTAL & 2.028 .753 & 100,00 & 35.861 & 100,00 \\
\hline
\end{tabular}


Tabela 3 - Quantidades e respectivas porcentagens de dormentes comuns e especiais refugados de acordo com o tipo de defeito observado.

\begin{tabular}{|l|r|r|r|r|}
\hline \multirow{2}{*}{ Tipo de defeito } & \multicolumn{2}{|c|}{ Dormentes comuns } & \multicolumn{2}{c|}{ Dormentes especiais } \\
\cline { 2 - 5 } & Quantidade & Porcentagem & Quantidade & Porcentagem \\
\cline { 2 - 5 } 1. Racha longitudinal & 113.661 & 58,81 & 1.858 & 32,33 \\
2. Esmoado & 34.670 & 15,25 & 161 & 2,80 \\
3. Racha anelar & 17.706 & 7,79 & 851 & 14,81 \\
4. Desbitolamento & 10.960 & 4,82 & 209 & 3,64 \\
5. Medula oca & 8.911 & 3,92 & 1.899 & 105 \\
6. Podridão & 8.268 & 3,64 & 260 & 3,04 \\
7. Furos de broca & 8.026 & 3,53 & 59 & 1,83 \\
8. Espécies não aceitas & 4.605 & 2,03 & 4,52 \\
9. Nós & 469 & 0,21 & 84 & 1,03 \\
10. Empenamento & - & - & - & 0,77 \\
11. Alburno & 227.276 & 100,00 & 1,46 \\
\hline TOTAL & & & 3,77 \\
\hline
\end{tabular}




\begin{tabular}{|c|c|c|c|c|c|c|c|c|c|c|c|c|c|c|c|c|c|c|c|c|c|c|c|c|c|c|c|}
\hline 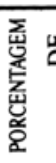 & 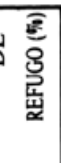 & 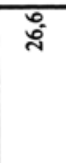 & \begin{tabular}{l}
$\infty$ \\
\multirow{2}{*}{}
\end{tabular} & $\begin{array}{l}\circ \\
\circ\end{array}$ & $\bar{m}$ & $\underset{\pi}{\tilde{\lambda}}$ & $\stackrel{\mathrm{m}}{\varrho}$ & ज्ञ & ¿̊ & 응 & है & $=$ & $=$ & 过 & 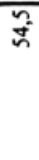 & & & 8 & 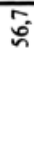 & & & 8 & 8. & 8 & & & \begin{tabular}{|l|} 
\\
$\infty$ \\
0
\end{tabular} \\
\hline $\begin{array}{l}\text { 㟔 } \\
\text { 宅 } \\
\text { 晋 }\end{array}$ & 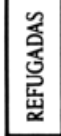 & \& & ఫ్స & $\stackrel{\infty}{=}$ & $\stackrel{\infty}{ల}$ & 5 & $\overline{6}$ & $\underline{a}$ & $\bar{\Xi}$ & $\approx$ & $m$ & & 5 & $=$ & $\stackrel{\text { N }}{ }$ & $\overline{7}$ & 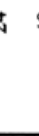 & f & $=$ & & t & & & $\infty$ & & \& & 娄 \\
\hline 放 & 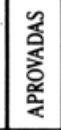 & $\stackrel{\Xi}{\Xi}$ & $\stackrel{\infty}{\curvearrowleft}$ & $\stackrel{\infty}{\varrho}$ & సี & $\stackrel{œ}{\varrho}$ & 导 & 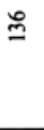 & 0 & 0 & సి & 5 & tr & $m$ & సి & $=$ & $=$ & 0 & $m$ & 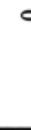 & b & 0 & 0 & $\circ$ & & $\bar{m}$ & 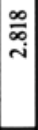 \\
\hline \multirow[b]{4}{*}{ 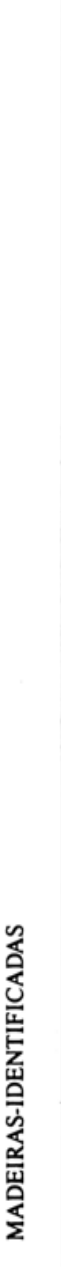 } & 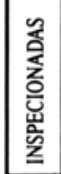 & $\stackrel{\infty}{\stackrel{\infty}{\underline{n}}}$ & مू & స్ల & \&్స & ચે & $\cong$ & $\cong$ & $\bar{\Xi}$ & $\approx$ & สี & 5 & $\overrightarrow{0}$ & ஜ & J & $=$ & f & \& & ల్ల & 5 & U & శి & $=$ & $\infty$ & & ల్ల & $\begin{array}{l}\text { Tे } \\
\text { for }\end{array}$ \\
\hline & 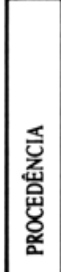 & 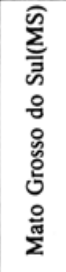 & 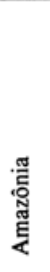 & 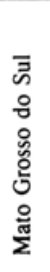 & 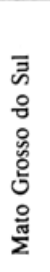 & 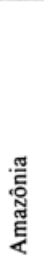 & 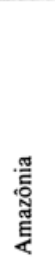 & 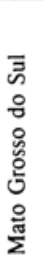 & 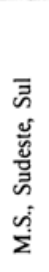 & 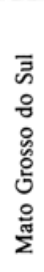 & 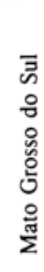 & 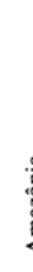 & 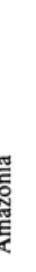 & 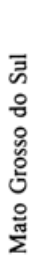 & 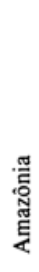 & 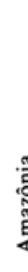 & 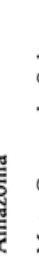 & 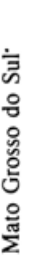 & 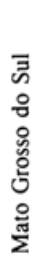 & $\begin{array}{l}3 \\
y \\
y\end{array}$ & 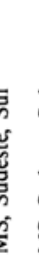 & 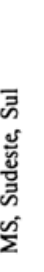 & 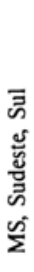 & $\begin{array}{l}\bar{n} \\
\frac{n}{2}\end{array}$ & & & \\
\hline & 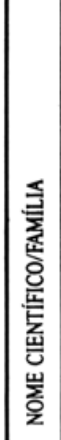 & 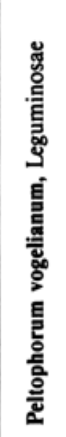 & 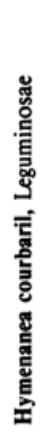 & 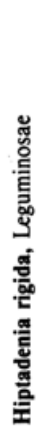 & 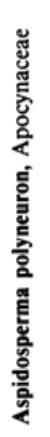 & 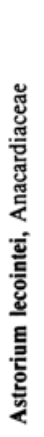 & 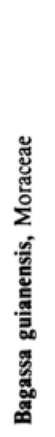 & 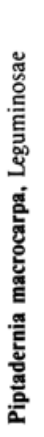 & 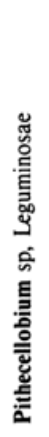 & 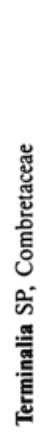 & 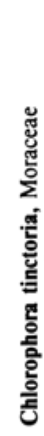 & 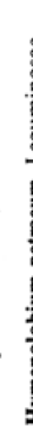 & 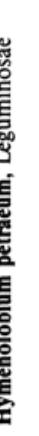 & 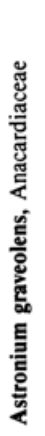 & 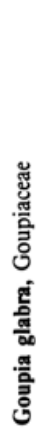 & d & 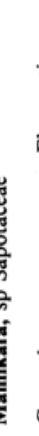 & 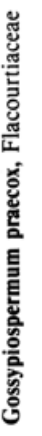 & 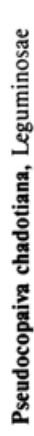 & & 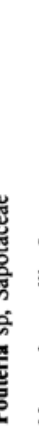 & 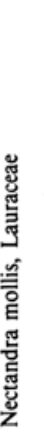 & 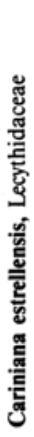 & 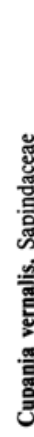 & & i & \\
\hline & 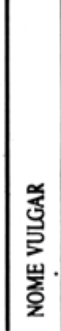 & 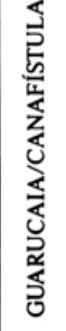 & 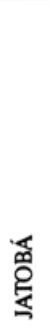 & 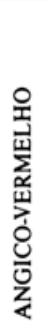 & 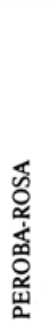 & 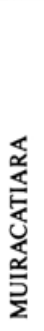 & 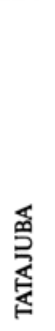 & 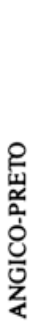 & 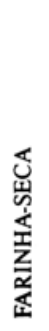 & 是 & 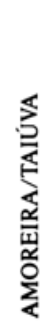 & 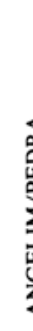 & 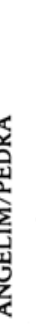 & 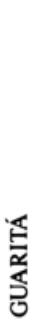 & 吕 & s & 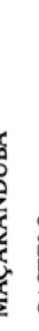 & $\frac{9}{\frac{3}{5}}$ & 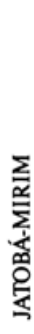 & & 童 & 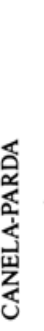 & 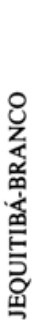 & 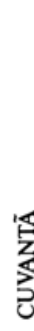 & & & t్ \\
\hline
\end{tabular}




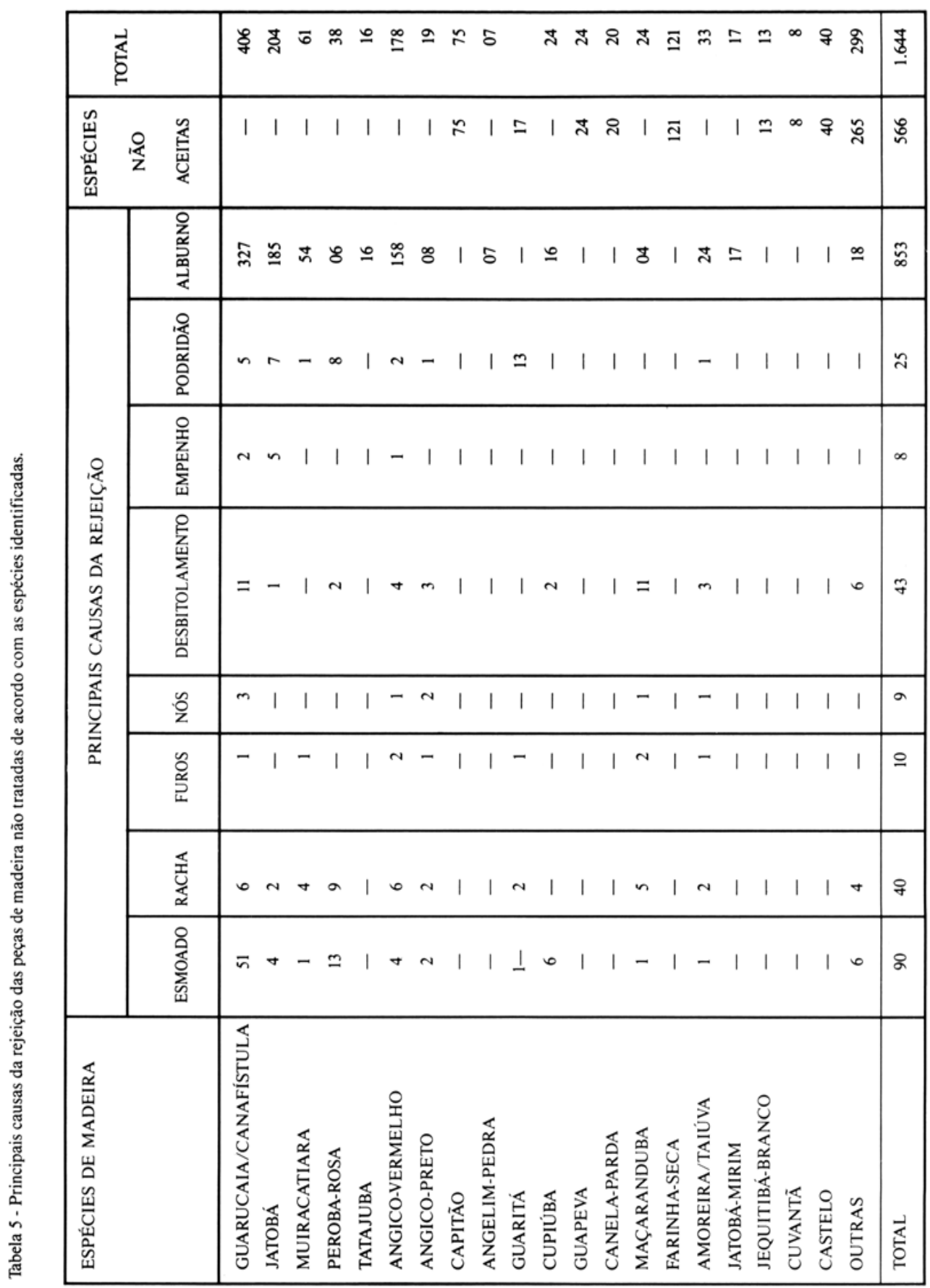

